\title{
AUTONOMIA MUNICIPAL E CRIAÇÃO DE GOVERNOS LOCAIS: A PECULIARIDADE INSTITUCIONAL BRASILEIRA
}

\author{
Fabricio Ricardo de Limas Tomio*
}

RESUMO: Este artigo aborda a autonomia municipal e a criação de governos locais. As instituições brasileiras são comparadas à realidade institucional e à fragmentação de governos locais em outros países. Esta comparação fornece os elementos para a problematização do papel dos governos locais no federalismo brasileiro. A institucionalização de uma federação em três níveis é um fenômeno político brasileiro. Esta peculiaridade institucional determina um alto grau de instabilidade na federação e impede que a dinâmica na fragmentação de governos locais resulte de um planejamento coordenado dos níveis mais abrangentes de governo. Diferentemente dos municípios brasileiros, os governos locais de outros países possuem um grau muito limitado de autonomia. No Brasil, a autonomia municipal é padronizada e estabelecida pela Constituição Federal. Entretanto, poucos municípios têm a capacidade de exercer a autonomia política, gerar recursos fiscais, administrar as demandas locais e executar políticas públicas. A ausência de variações na definição das funções e competências dos municípios, pela via constitucional ou por delegação dos estados, cria expectativas irrealizáveis na maior parte dos governos locais. Os pequenos municípios comportam-se mais como grupos de interesse com status público do que como organizações governamentais. As grandes municipalidades são proibidas de gerir políticas que poderiam executar com maior racionalidade, eficácia e controle público do que as esferas mais abrangentes. A autonomia municipal brasileira apresenta questões ao estudo das instituições políticas brasileiras: a crítica do arranjo institucional do federalismo, o papel dos níveis de governo, os mecanismos de estímulo à cooperação/competição entre as entidades governamentais.

\section{INTRODUÇÃO}

* Professor Adjunto do Departamento de Direito Público (UFPR) e Doutor em Ciência Política (IFCH/ UNICAMP).
A Constituição Federal de 1988 gerou um novo ordenamento federativo. Os constituintes não só estabeleceram as bases do estado 
democrático, também instituíram um novo

"pacto federativo". Em quase todas as constituições (exceto na carta de 1937) os municípios foram definidos como organizações políticas autônomas. Contudo, somente a Constituição de 1988 atribuiu uma autonomia plena aos municípios, elevando-os ao status de ente federativo, com prerrogativas invioláveis por qualquer nível mais abrangente de governo. Esta situação peculiar não é identificável em outros países organizados numa federação. Na maioria das federações os municípios ou outros níveis de poder local são divisões administrativas das unidades federadas, que delegam (ou não) diferentes níveis de autonomia administrativa aos governos locais. No caso brasileiro, o último arranjo institucional gerou uma federação com três níveis constitucionalmente autônomos compartilhando a soberania: a União, os estados (e o Distrito Federal) e os municípios. ${ }^{1}$

1 Essa configuração institucional peculiar é resultante do texto da última carta constitucional (BRASIL, 1988). Antes de 1988, muitos juristas não consideravam a federação brasileira como uma organização política de três graus distintos. Ataliba, por exemplo, afirmava que, mesmo não sendo hierarquicamente subordinado, o município "não integra a Federação", sendo sua autonomia somente "uma forma qualificada de descentralização política" (Ataliba, 1987, p. 73-5). Já Montoro definia o município brasileiro como uma "entidade estatal rígida" que, a exemplo dos estados membros de uma federação, possui competências atribuídas pela Constituição Federal: como o poder de império, o poder político e a autonomia administrativa, política e legislativa. Entretanto, não seriam entidades federativas de mesma natureza, porque, diferentemente dos estados, os municípios: não possuíam (antes de 1988) poder de auto-organização (Constituição ou Lei Orgânica), não participavam da formação da vontade geral (através de um órgão legislativo como o Senado Federal) e não possuíam poder de dominação própria (órgãos judiciários para a aplicação do direito
A descentralização político-institucional foi acompanhada da ampliação de recursos fiscais e das competências tributárias dos municípios e do mais expressivo processo de fragmentação dos municípios brasileiros. Esta situação, sem similar recente em outros estados nacionais, despertou preocupações sobre as consequiências da falta de estabilidade no ordenamento federativo, do desperdício fiscal e da instabilidade na gestão das políticas públicas. ${ }^{2}$

municipal) (MONTORO, 1974, p. 105-111). Mesmo caracterizando o município antes da promulgação da Constituição de 1988, esses autores identificaram o alto grau de autonomia municipal, que foi radicalizado na nova carta. Os municípios conquistaram o poder de auto-organização através de Leis Orgânicas votadas pelas Câmaras Municipais, tal qual as constituições estaduais. Isto só existia anteriormente no Rio Grande do Sul, enquanto delegação de um poder estadual aos municípios (MONTORO, 1974, p.122). Sobre as características institucionais do município no federalismo brasileiro, ver também, Giannini (1990), Soares (1998), Mello (1993), Castro (1987), Affonso e Silva (1995a; 1995b).

2 Para entender a relação entre descentralização e democratização no Brasil são interessantes as seguintes referências: o trabalho de Arretche (1995; 1996), que aborda a confusão no uso desses termos, polemizando sobre a continua vinculação entre eles na literatura; também, nesse aspecto, são interessantes os trabalhos de Tobar (1991) e Uga (1991); o debate sobre a descentralização fiscal e a fragilidade dos municípios em Gomes e Macdowell (1997); a relação entre cidadania e estruturas de governo local em Fischer (1993) apresenta subsídios sociológicos relevantes ao debate; sobre a heterogeneidade do processo de descentralização das políticas sociais, ver Castro (1991), Arretche (1995; 1998; 1999), Almeida (1995), Medina (1987), Teixeira (1992; 1994) e Baêta (1989); sobre o aumento do poder político dos governantes estaduais, ver Abrúcio e Samuels (1997) e Abrúcio (1998); a respeito da ideologia municipalista, ver Melo (1993); e, sobre a defesa das emancipações municipais como um meio para reforçar a democracia e a descentralização política, são relevantes os trabalhos dos técnicos do IBAM/RJ e CEPAM-FPFL/SP, sobretudo Bremaeker (1991; 1993), Jacobi (1990; 1991) e Mello (1991; 1992). 
Após a promulgação da Constituição Federal de 1988 foram criados 1.385 municípios no Brasil (cerca de $25 \%$ dos 5.564 hoje existentes ou $33 \%$ de acréscimo sobre os 4.179 que existiam em 1988). Esta instabilidade institucional no ordenamento federativo gerou uma reação que culminou na aprovação da Emenda Constitucional 15/1996 pelo Congresso Nacional. Uma centralização política que reeditou a violação da federação ocorrida em períodos não democráticos. ${ }^{3}$

O último surto de fragmentação municipal ocorreu durante a redemocratização, tomando impulso após a promulgação da Constituição de 1988. Em virtude disto, muitos autores sugeriram que a variação no regime político determinaria o ritmo da criação de municípios devido à descentralização política, institucional e fiscal. ${ }^{4} \mathrm{O}$ processo de fragmentação

\footnotetext{
3 A Emenda 15/96, da mesma forma que o Regime Militar através da Constituição de 1967 e da Lei Complementar 01/67, retirou das unidades federadas a autonomia de regulamentar sua divisão político-administrativa interna. A partir dessa emenda o processo de fragmentação municipal voltou a ser regulamentado por Lei Complementar Federal. O resultado foi a interrupção do processo emancipacionista, que se encontra suspenso devido à ausência de regulamentação sobre a matéria

4 Este tipo de explicação, que define o regime político como variável independente da intensidade de emancipações municipais, apesar de não totalmente equivocada, é muito genérica e não apresenta os mecanismos políticos e institucionais específicos que determinariam a ocorrência das "ondas" ou "surtos" de fragmentação municipal. Na literatura, essa tese tem sua melhor construção e argumentação desenvolvida por Gomes e Macdowell (1997). Similarmente, Shikida (1998) relaciona a estrutura do federalismo brasileiro à ocorrência do fenômeno político emancipacionista, por meio do conceito "restrição orçamentária não rígida", no qual as transferências intergovernamentais (FPM), em
}

municipal recente não é resultado direto do regime político, um efeito da democratização, mas foi gerado por fatores políticos e institucionais mais específicos e, sobretudo, por decisões legislativas estaduais.

O mesmo contexto institucional geral moldou o ambiente de decisão política que predispôs a criação de novos municípios a partir da década de oitenta em todo Brasil (descentralização fiscal e do processo de fragmentação política). Entretanto, poucos estados foram responsáveis pela maior parte dos novos municípios. Aquelas unidades da federação onde os legisladores estaduais aprovaram uma regulamentação estadual que determinou uma grande potencialidade multiplicadora de municípios. Principalmente, através da aprovação de leis complementares que determinaram os passos do processo de criação de município e os limites ou

regimes democráticos, incentivariam os atores a decidir favoravelmente pela emancipação onde fosse possível ampliar a disponibilidade de recursos às localidades emancipadas. Outras explicações, menos plausíveis que a vinculação direta com o regime político, fundamentam-se em vários aspectos do processo emancipacionista (causas societais e políticas) e variam muito quanto à abordagem teóricoepistemológica adotada. Porém, na maior parte dos casos, simplesmente não se sustentam diante de uma avaliação lógica ou de um teste empírico mais elaborado. Há explicações orientadas por uma abordagem funcionalista, como a de Bremaeker, segundo a qual as emancipações municipais responderiam a "uma lógica extremamente racional" (1991, p. 33). Outra explicação similar a anterior é desenvolvida por Mesquita. Utilizando uma abordagem sistêmica, a autora define que as causas últimas das emancipações municipais estariam no processo de modernização (MESQUITA, 1992, p. 170). Há, ainda, outras explicações para o fenômeno, como a apresentação de causas institucionais em Mello (1992); as explicações das emancipações pelas motivações dos atores locais (BREMAEKER, 1993; KLERING, 1991). 
exigências às localidades que desejavam seu desmembramento. Portanto, foi o processo de decisão política de alguns estados, onde estímulos fiscais (federais) e instrumentos processuais favoráveis (estaduais) se encontraram, formando um contexto institucional permissivo à fragmentação municipal, que gerou os milhares de novos municípios durante a década de noventa no Brasil. 5

Esta breve apresentação do processo de multiplicação dos municípios permite recolocar o problema, normativo e políticoinstitucional, do papel dos governos locais no federalismo brasileiro e definir o objetivo central deste artigo: a contextualização do caráter peculiar da fragmentação e autonomia municipal brasileira, comparada a situações similares em outros estados nacionais.

\section{FEDERALISMO, AUTONOMIA POLÍTICA E CRIAÇÃO DE GOVERNOS LOCAIS}

A fragmentação e a autonomia dos municípios no federalismo brasileiro pode ser problematizada, numa dimensão comparativa e normativa, a luz da literatura internacional que descreve ou analisa a criação de unidades de governo local. A primeira distinção observada, entre o

5 Em um estudo comparativo procurei demonstrar que a intensidade emancipacionista possui uma variação determinada conforme: a disponibilidade de localidades emancipáveis, a posição resultante da relação de forças entre o executivo e o legislativo estaduais e a presença de mecanismos institucionais federativos que transfiram recursos aos governos locais e que favoreceram a autonomia do legislativo estadual. Ver Tomio (2002a; 2002b). processo brasileiro e qualquer evento similar relatado em outros países, é a quantidade de novas unidades locais criadas. A realidade brasileira nessa área é singular, não existindo qualquer referência contemporânea a uma fragmentação interna tão acentuada.

Os exemplos de criação de novas unidades de governo local (new towns) indicam, normalmente, um planejamento mínimo dos níveis superiores de governo. Geralmente, esses se referem à criação ou reorganização de áreas suburbanas em grandes metrópoles. Como há uma intencionalidade políticoadministrativa na criação destas unidades locais, os aspectos problematizados não são as causas, mas os efeitos urbanísticos, sócioculturais e comportamentais que a criação das new towns acarretam. Alguns estudos desse tipo presentes na literatura tratam sobre: o empobrecimento e homogeneização populacional na new town de Elisabeth, na Austrália (PEEL, 1995); o financiamento e planejamento, público e privado, no desenvolvimento de new towns em várias províncias canadenses (SKABURSKIS, 1989); as conseqüências do deslocamento populacional para as new towns das cidadesestado de Hong Kong e Singapura (VASOO, 1988); o comportamento social, o espírito comunitário e a satisfação dos moradores de new towns britânicas (BARDO e BARDO, 1983); a crise e os problemas sociais nas cinco novas cidades da área metropolitana de Paris (criadas na década de 60) e os limites do planejamento público na estruturação das mesmas (GOURSOLAS e ATLAS, 1980; DAGNAUD, 1981).

Contrastando com a experiência brasileira recente, todos estes casos relacionam a criação de unidades administrativas locais ao processo 
de urbanização. Ou, mais especificamente, à expansão populacional de grandes núcleos urbanos ou metrópoles. No Brasil, a maioria dos novos municípios não está interligada às principais zonas urbanas, mas é o resultado da fragmentação de pequenos municípios do interior. Muitos destes são, inclusive, comunidades predominantemente rurais que perderam população nas últimas décadas.

Além disto, com exceção das regulamentações sobre a criação de municípios em cada estado brasileiro, não existe qualquer planejamento centralizado nas esferas superiores de governo sobre a fragmentação territorial e o funcionamento dos novos municípios. Os estudos que focalizam os impactos econômicos, políticos, sociais e fiscais ocorreram posteriormente ao início da onda de fragmentação municipal brasileira, tendo pouco ou nenhum efeito sobre as unidades locais que continuaram a ser criadas. Em síntese, comparada à ocorrência de processos similares, a criação de municípios no Brasil distingue-se por ser muito mais numerosa, concentrada em áreas pouco urbanizadas e não ser ordenadamente planejada pelos níveis de governo mais abrangentes.

$\mathrm{Na}$ literatura internacional há duas explicações para o processo de fragmentação territorial. Procurando identificar possíveis causas à criação de unidades locais, Wright (1975) e Caputo (1975) argumentam sobre o papel do "general revenue sharing"6 (um programa de transferência de recursos fiscais do nível federal para as unidades subnacionais) na organização, incremento, extinção ou fusão de governos locais nos Estados Unidos (ver a evolução na quantidade dos governos subnacionais norte-americanos na Tabela 1$){ }^{7}$

TABELA 1 - UNIDADES DE GOVERNO SUBNACIONAIS NOS ESTADOS UNIDOS (1942-1992)

\begin{tabular}{l|r|r|r|r|r|r}
\hline \multicolumn{1}{c}{ TIPOS DE GOVERNO } & \multicolumn{1}{c|}{1942} & \multicolumn{1}{c|}{1952} & \multicolumn{1}{c|}{1962} & 1972 & \multicolumn{1}{c}{1982} & \multicolumn{1}{c}{1992} \\
\hline Estados & 48 & 48 & 50 & 50 & 50 & 50 \\
Condados & 3.050 & 3.049 & 3.043 & 3.044 & 3.041 & 3.043 \\
Municipalidades (Cities e Towns) & 16.220 & 16.778 & 18.000 & 18.516 & 19.076 & 19.279 \\
Townships & 18.919 & 17.202 & 17.142 & 16.991 & 16.734 & 16.656 \\
Distritos Especiais & 8.299 & 12.319 & 18.323 & 23.886 & 28.078 & 31.555 \\
Distritos Escolares & 108.579 & 67.346 & 34.678 & 15.780 & 14.851 & 14.422 \\
\hline TOTAL & 155.115 & 116.742 & 91.236 & 78.267 & 81.830 & 85.005 \\
\hline
\end{tabular}

FONTE: Wright (1975, p. 102), Pagano (1990, p. 96), Estados Unidos (1994, p. 15)

6 Segundo Caputo (1975, p. 131-4), o "general revenue sharing" foi um programa, iniciado em 1972, de transferência de recursos fiscais (do governo federal para os governos locais) nos Estados Unidos, sendo uma das iniciativas políticas de descentralização do "new federalism" no governo Nixon. Esse tipo de transferência apresentaria três diferenças com relação a outros programas federais de ajuda a estados e governos locais americanos: primeiro, tinha provisões de fundos por cinco anos, reduzindo o controle anual dos congressistas sobre os recursos; segundo, permitia aos governos estaduais e locais uma grande liberdade na alocação dos recursos transferidos; terceiro, havia pouco controle burocrático sobre a aplicação dos recursos.

7 Dos três tipos de governos locais com propósitos gerais: 1) os condados ("county governments") existem em quase todo território norte-americano, menos em Connecticut, Rodhe Island, District of Columbia e em algumas porções de outros estados (e são 
Os autores concluem que os efeitos das transferências foram marginais na organização dos governos locais americanos. Segundo Wright (1975, p. 102), a fusão/extinção de distritos educacionais e a criação de novos distritos especiais, ${ }^{8}$ principais elementos dinâmicos na estrutura de governos locais, ocorreu independentemente do "general revenue sharing", visto que ambos estavam excluídos do programa. A redução na quantidade de distritos educacionais atenderia a um processo de racionalização

denominados parish em Louisiania e borough no Alaska), sendo que, entre 1987 e 1992, foram criados três novos condados no Alaska e extintos outros dois devido à fusão com municipalidades; 2) as municipalidades ("municipal governments") são distintas das townships por razões históricas e designam um "governo geral para uma concentração populacional específica de uma determinada área" e incluem diversas denominações estaduais (cities, boroughs, towns, villages), foram criadas 79 (quase todas na California, North Carolina e no Texas) e extintas 5 unidades (em Vermont) entre 1987 e 1992; 3) os "township" ou "town governments" existem em 20 estados do nordeste e meio-oeste americano com vários nomes (plantations, locations, municipal corporations e towns, que nem sempre são áreas predominantemente rurais), foram extintas 35 dessas unidades entre 1987 e 1992. Existem, em todos os três tipos, governos locais com cem ou menos habitantes e alguns condados e municipalidades com milhões de habitantes (Estados Unidos, 1994, p. 7-9).

8 Os distritos educacionais e os distritos especiais são unidades de governo local destinadas a um único propósito, diferenciadas, portanto, dos condados, municipalidades e townships que possuem propósitos gerais. Estes distritos existem na maioria dos estados americanos, sendo que cada distrito especial, que pode ou não ter a capacidade de cobrar impostos, tem jurisdição sobre as mais variadas áreas (portos, aeroportos, irrigação, parques, controle de desastres, combate ao fogo, hospitais, controle de pragas, cemitérios, etc.) com exceção da educação, que é uma área exclusiva aos distritos educacionais ou aos governos com propósitos gerais (Estados Unidos, 1994, p. 9-11). administrativa, em curso desde os anos 40 . Enquanto o incremento dos distritos especiais seria resultante de outro processo, decorrente das políticas tributárias federais e estaduais: a crescente limitação na capacidade de cobrar taxas e impostos pelos outros governos locais, ${ }^{9}$ que estariam transferindo a administração de políticas específicas para esses distritos.

Já os efeitos do "general revenue sharing" sobre a fragmentação dos governos locais com propósitos gerais teriam sido periféricos. Mais do que fomentar a criação de novas unidades, visto que os valores transferidos representariam menos de $10 \%$ dos recursos disponíveis ao conjunto destes governos, ${ }^{10}$ a garantia de transferências federais teria promovido a preservação de algumas estruturas locais de governo. Assim, segundo a hipótese de Wright (1975, p. 103-4), os efeitos do programa de transferências sobre a fragmentação, extinção ou fusão dos governos locais americanos teriam sido: nulos, para os condados; limitados, para as municipalidades, já que as novas unidades criadas seriam resultantes da urbanização em áreas metropolitanas; e, um pouco mais relevantes, para as townships, já que teria limitado o declínio na quantidade dessas unidades.

9 Sobre as restrições a capacidade de impor taxas pelos governos locais nos EUA, ver Pagano (1990, p. 97-9).

${ }^{10}$ Segundo Wright (1975, p. 103-4), o programa de transferências federais "general revenue sharing" representaria, em 1972, 9\% dos recursos fiscais dos condados, $8 \%$ das municipalidades e $10 \%$ das townships. Como o autor só especifica os valores agregados, torna-se impossível fazer comparações com transferências semelhantes no Brasil (como o FPM) e o impacto em governos locais com diferentes níveis populacionais. 
Nas constatações desses autores sobre o federalismo americano e a fragmentação das unidades de governo local, quando comparadas ao caso brasileiro, aparecem, direta ou indiretamente, três questões relevantes para esta investigação. Primeiro, há a tentativa de relacionar a disponibilidade de recursos fiscais à criação ou à sobrevivência de governos locais. A existência de mecanismos institucionais que garantiriam a transferência, das esferas mais abrangentes de governo, de um valor mínimo que, somado as outras receitas, permitiria a funcionalidade das unidades locais é um fator explicativo relevante ao problema (e, como tal, tem sido mencionado na literatura de ambos países). $\mathrm{Se}$, no caso norte-americano, um programa federal de cinco anos com recursos relativamente marginais teria influenciado na preservação de unidades subnacionais; no caso brasileiro, a perenidade de fundos constitucionais que garantem a maior parte dos recursos fiscais da maioria dos governos locais deveriam ter (como de fato parecem ter tido) efeitos muito mais amplos (enquanto estímulo institucional) sobre a fragmentação de municípios.

O limite das explicações que se fundamentam na equação disponibilidade de recursos fiscais determina a fragmentação dos governos locais é a excessiva importância atribuída a esta relação causal. A transferência de recursos, única ou exclusivamente, não explicaria a criação/preservação de unidades de governo local. Como a repartição fiscal é uma prática frequiente em vários países, ${ }^{11} \mathrm{o}$

${ }^{11}$ As próprias unidades de governo local norteamericanas são majoritariamente dependentes de transferências fiscais das esferas mais abrangentes de governo ("federal and state aid"). Em conjunto, papel da transferência seria limitado a estimular o processo. Contudo, outros condicionantes institucionais teriam maior importância na geração de um ambiente político favorável à ocorrência de uma fragmentação acelerada dos governos locais.

Segundo, a questão normativa que orienta esses e outros autores norteamericanos (principalmente na década de setenta) não parece ser a preocupação, favorável ou contrária, com a ocorrência de uma grande onda de novos governos locais. Mas o retardamento do processo inverso, de fusão ("consolidation") desses governos em favor de uma maior eficácia administrativa, sobretudo nas áreas metropolitanas e outras conurbações. Seyler (1974, p. 159-69), por exemplo, enfatiza a necessidade de cooperação entre as unidades locais, através da fusão entre condados e municipalidades ou do estabelecimento de conselhos regionais de gestão. ${ }^{12}$ Marando (1973, p. 95-6), sem enfatizar tanto uma posição normativa, procura explicar o insucesso na fusão entre condados e municipalidades através das expectativas negativas dos eleitores (manifestadas em referendos), que, entre outros fatores, identificariam na fragmentação administrativa (entre condados, municipalidades e distritos especiais) uma maior capacidade na provisão de serviços públicos. Já Zimmerman (1974,

esses recursos representaram, nas últimas décadas, mais da metade do orçamento dos governos locais (Nathan e Lago, 1990).

${ }^{12} \mathrm{O}$ autor fornece o exemplo da incorporação administrativa entre o condado de Los Angeles e 77 municipalidades dentro de seus limites; da fusão de condados e municipalidades por referendo popular ou lei estadual (caso de Indianapolis); e dos conselhos administrativos regionais na Pennsylvania (SEYLER, 1974, p. 162-3). 
p. 134-41) afirma que a fragmentação jurisdicional existente nas metrópoles seria o fator responsável por alguns problemas do modelo administrativo local americano, sendo que o estado teria um papel importante na definição de regras que estimulassem a racionalização administrativa. ${ }^{13}$

O volume da fragmentação municipal brasileira, na última década, parece ter deixado muito pouco espaço para proposições criativas quanto à organização e as interrelações dos governos locais. O embate normativo foi muito extremado, sendo comum a defesa ou condenação intransigente da criação de novos municípios. O debate sobre formas de cooperação intergovernamental e alternativas institucionais locais na estrutura federativa nunca fizeram parte da agenda política, sendo marginalmente discutidos nos espaços de decisão política.

Terceiro, há uma grande diferenciação na estrutura das divisões político-administrativas internas dos Estados Unidos e do Brasil. Isto implica em graus muito diversos de autonomia dos governos locais e, por conseguinte, de impactos distintos provocados pela fragmentação das unidades subnacionais. Esta questão fornece novos subsídios ao debate normativo sobre a fragmentação municipal brasileira e é complementada pela comparação da extensão de atribuições e da quantidade de unidades de governo local em cada país.

Alguns autores brasileiros advogam favoravelmente à criação de municípios devido à seguinte comparação: no Brasil haveria um número pequeno de municípios e a relação entre município/área ou município/ população seria muito extensa quando comparado a outros países, como a França e os Estados Unidos, que estão entre os mais pródigos em unidades de governo local (aproximadamente quarenta mil unidades cada). Este, a meu ver, é um argumento absurdo, visto que a organização políticoadministrativa e o grau de autonomia municipal desses países são muito distintos da brasileira (ver Tabela 2). ${ }^{14}$

TABELA 2 - GRAU DE AUTONOMIA/DEMOCRATIZAÇÃO INSTITUCIONAL DOS MUNICÍPIOS (OU SIMILARES)

\begin{tabular}{l|l|l|l}
\hline Países & $\begin{array}{l}\text { Separação de Poderes e } \\
\text { Eleição Autônoma dos } \\
\text { Governantes }\end{array}$ & $\begin{array}{c}\text { Autonomia Local } \\
\text { (Independência das } \\
\text { Decisões) }\end{array}$ & $\begin{array}{c}\text { Capacidade de Gerar } \\
\text { Recursos Próprios }\end{array}$ \\
\hline Brasil & Generalizada & Muito Extensa & $\begin{array}{l}\text { Existente, definida pela } \\
\text { Constituição Federal }\end{array}$ \\
\hline França & Parcial & Pouco Extensa & $\begin{array}{l}\text { Restrita, supervisionada } \\
\text { pelo Governo Central }\end{array}$ \\
\hline Estados Unidos & $\begin{array}{l}\text { Variável, conforme o } \\
\text { estado e entre os governos } \\
\text { locais dos estados }\end{array}$ & $\begin{array}{l}\text { Variável, conforme o } \\
\text { estado e entre os governos } \\
\text { locais dos estados }\end{array}$ & $\begin{array}{l}\text { Variável, conforme o } \\
\text { estado e entre os governos } \\
\text { locais dos estados }\end{array}$ \\
\hline
\end{tabular}

FONTE: Estados Unidos (1994), França (1996) e Teune (1995, p. 20-3).

${ }^{13}$ A respeito da fusão entre municipalidades e condados, ver também o estudo de caso que avalia os benefícios da anexação da city of Danville pelo Pittsylvania county, em Virginia (CRAVER, 1999).
${ }^{14} \mathrm{O}$ modelo para identificação do grau de autonomia/democratização utiliza como base as três variáveis fundamentais, conforme definidas por Teune (1995, p. 20-3), para verificação do desenvolvimento 
A França tem uma organização territorial estruturada em quatro níveis hierarquizados: o Estado, a Região, o Departamento e o Município. A grande quantidade de municípios está vinculada à forma de sua instituição, ocorrida em 1789 ("um município em cada vila, burgo, paróquia ou comunidade de província"). ${ }^{15}$ Entretanto, apesar de numerosos ou talvez por causa disso, os municípios franceses possuem um grau muito reduzido de autonomia. Somente o "conselho municipal", com o número de membros proporcionais à população, é eleito diretamente pela comunidade, sendo que seu poder deliberativo é restrito e orientado pelas instâncias superiores. $\mathrm{O}$ administrador municipal é eleito pelo conselho e, dentro de um sistema dual, executa as deliberações locais e representa o Estado no município, subordinando-se ao nível hierárquico superior (o departamento). A capacidade tributária municipal é restrita e quanto menor a população local maior é a supervisão orçamentária da burocracia estatal sobre o município (MELLO, 1993; FRANÇA, 1996).

Neste modelo de estado unitário francês, adotado em suas linhas principais por outros

político democrático dos governos locais: 1) a eleição de governantes diretamente pela comunidade local e a separação de poderes entre executivo e legislativo, como procedimentos independentes dos níveis de governo mais abrangentes; 2) a autonomia das decisões tomadas por esses governantes ("home-rule") e sua independência (não confirmação ou regressão) com relação às autoridades dos níveis superiores; 3) a autoridade local para taxar e coletar recursos fiscais independentemente, mesmo que em pequena escala.

${ }^{15}$ Mais de $80 \%$ dos municípios tem menos de mil habitantes, razão pela qual o governo central vem fomentando o seu reagrupamento em "sindicatos intercomunais" (FRANÇA, 1996, p. 2). países europeus, latino-americanos e africanos (MELLO, 1993, p. 39), a problematização das causas da criação de municípios não tem sentido, visto que estes têm institucionalização imediata diante da ocorrência de uma nova comunidade. Isso não significa dizer que os efeitos da fragmentação territorial sejam meramente administrativos, já que a recente reforma francesa indica uma pressão política pela descentralização. Contudo, dentro de uma estrutura tão centralizada e hierarquizada, o gerenciamento do efeito desestabilizador de uma possível onda de fragmentação municipal seria, provavelmente, mais eficaz.

O outro caso destacado, a organização territorial norte-americana é muitas vezes visto como o modelo típico de estrutura federalista. Os estados, enquanto unidades federadas, possuem total independência na definição da quantidade, tipos, formas e grau de autonomia das unidades de governo local dentro de suas fronteiras. ${ }^{16}$ Nos EUA, não há uma padronização de nomes para os governos locais, que podem variar conforme os estados. Para efeito estatístico o Bureau of the Census agrupa os governos locais em

${ }^{16}$ A doutrina constitucional norte-americana (conhecida como Dillon's Rule, devido ao nome do juiz da Suprema Corte que a estabeleceu no século XIX) define as unidades locais como criaturas do governo estadual que, por princípio, poderia criálas ou extingui-las livremente, a despeito dos interesses locais. Neste sentido, os condados, municipalidades e outros tipos de governos locais não são entes federativos, sendo que sua eventual autonomia é fruto de delegação dos legisladores estaduais. Na prática, contudo, apesar do "home rule" não ser garantido necessariamente, há uma histórica tradição de respeito à autonomia dos governos locais norte-americanos na maioria dos estados federados (RUTLEDGE, 1974; GRUMM e MURPHY, 1974; PAGANO, 1990). 
cinco tipos: três com propósitos gerais (condados, municipalidades e townships) e dois com propósitos específicos (distritos educacionais e especiais).

Em virtude desta diferenciação interna, existe uma grande variação nas configurações que determinariam o grau de autonomia das unidades locais. Há localidades que elegem: prefeitos e representantes (legislativo); só os representantes que, por sua vez, nomeiam prefeitos ou gerentes; e outras que possuem administradores indicados por instâncias superiores (Estados Unidos, 1994b). Dentre os diferentes tipos de governos locais, há pelo menos 31 estados que tem o "home rule" (independência nas decisões políticas em diversos graus) garantido aos condados em regulamentações estaduais (HILLENBRAND, 1974, p. 92); enquanto 30 estados delegam esse mesmo direito em suas constituições às cidades (PAGANO, 1990, p. 101-2). Da mesma forma, a capacidade de gerar recursos autonomamente varia conforme as limitações impostas pelas unidades da federação (PAGANO, 1990, p. 103-5). Entretanto, geralmente os tributos arrecadados localmente são significativos para o funcionamento destes governos, visto que podem representar até metade do total dos gastos das unidades locais (NATHAN e LAGO, 1990, p. 38).

Devido a estas características, a constante alteração na organização territorial norteamericana, com a criação ou extinção de unidades locais, parece ter seus efeitos limitados pela diferenciação do grau de autonomia delegado aos governos locais. Isto, junto com a prerrogativa dos estados em regulamentar integralmente a existência de suas subdivisões territoriais, permite respostas razoáveis tanto às demandas locais por autogoverno quanto à racionalidade administrativa e fiscal do estado. ${ }^{17}$

Contrastada com os dois exemplos anteriores, a dimensão da autonomia municipal brasileira e de sua relação com a onda de fragmentação municipal da última década pode ser mais bem avaliada. Apesar de ser uma federação, a divisão territorial brasileira segue padrões mais rígidos (mesmo que totalmente diferentes quanto ao conteúdo) do que no estado unitário francês, sendo que toda organização dos entes políticos internos está institucionalizada nos níveis jurídicos mais elevados (a maior parte na própria constituição federal, com um papel regulador menor sendo destinado às constituições estaduais e leis complementares). A federação é estruturada em três níveis (União, Estados/Distrito Federal e Municípios) não hierarquizados, mas eqüipolentes e autônomos, com suas competências políticas, administrativas e fiscais determinadas constitucionalmente.

O outro lado desta faceta institucional determina que, mesmo sendo uma federação, como os Estados Unidos, no Brasil os estados não possuam qualquer poder formal sobre a extensão e qualidade das decisões internas dos municípios, pois esse poder não foi

${ }^{17}$ A criação de uma unidade de governo local também poderia concentrar renda e limitar políticas fiscais redistributivas. Nos Estados Unidos, demandas locais por autogoverno podem significar a tentativa de segregação de comunidades por critérios étnicos, de renda etc., o que permitiria uma maior regressividade tributária à população segregada, pela apropriação exclusiva de tributos locais ou transferências intergovernamentais anteriormente distribuídos entre uma comunidade mais heterogênea. 
delegado pelos primeiros. ${ }^{18}$ Institucionalmente, sobre os assuntos municipais, somente cabe aos estados o poder de intervir (em casos definidos juridicamente); de definir a forma de distribuição de uma fração menor de um dos impostos que arrecada (o ICMS); e de regulamentar (entre 1988 e 1996) as condições mínimas exigidas à criação de um município em seu território, bem como decidir sobre a emancipação municipal. De todas estas competências, a última é que permite uma maior interferência do estado sobre a organização municipal.

Em virtude disto, a autonomia é universalizada e padronizada nos municípios brasileiros. Todos elegem da mesma forma os mesmos tipos de governantes (que só variam na quantidade de vereadores, conforme a população local), tem a mesma independência e as mesmas subdivisões político-administrativas (distritos) e podem cobrar os mesmos tipos de impostos. Independentemente da complexidade sócioeconômica, extensão geográfica, quantidade e densidade populacional, há somente uma forma de governo local.

Criar um município no Brasil, diferentemente da criação de unidades de governo local em outros países, significa gerar uma nova entidade federativa. Um novo município, com menos de mil habitantes, possui as mesmas prerrogativas dos municípios de milhões de pessoas.

${ }^{18}$ Estou tratando aqui somente dos aspectos formais. Na interação entre os atores políticos, governantes das diferentes instâncias administrativas, é possível ser estabelecidas relações de subordinação não previstas constitucionalmente. Esse seria o caso do poder de governadores sobre governantes locais, como argumenta Abrucio (1998).
Os impactos políticos de um processo de fragmentação, na dimensão verificada nas últimas décadas, devem ser muito mais acentuados no caso brasileiro. Sobretudo, porque não há mecanismos institucionais eficazes que permitam conciliar os interesses autonomistas locais com a racionalidade generalizante das esferas mais abrangentes de governo. Em virtude disto, as modificações institucionais inscritas nas últimas constituições não oferecem soluções a esse problema da federação brasileira, limitando-se a promover mecanismos restritivos ou permissivos às emancipações municipais em momentos políticos distintos. Ou, mais especificamente, nos últimos sessenta anos, com o estímulo das transferências fiscais inaugurados pela constituição de $1946,{ }^{19}$ quando foi atribuído aos estados determinar o processo de fragmentação dos municípios, a ocorrência de ondas de fragmentação municipal variou em intensidade nos estados conforme o arranjo institucional e a relação executivolegislativo na esfera estadual.

${ }^{19}$ A Constituição de 1946 , no $\$ 4 .^{\circ}$ de seu art. 15 , determinou a transferência, "em partes iguais" aos municípios do interior, de $10 \%$ da arrecadação do Imposto de Renda. A Emenda Constitucional n.o 5 de 1961 ampliou a participação dos municípios nesse imposto para $15 \%$. Além de ampliar o fundo com $10 \%$ da receita sobre o imposto de "consumo de mercadorias". O regime militar, através da Emenda Constitucional n. ${ }^{\circ} 18$ de 1965, instituiu uma nova ordem tributária que criou o FPM (Fundo de Participação dos Municípios). Esta medida diminuiu a participação dos municípios para $10 \%$ do IR e do IPI e determinou a forma de aplicação da maior parte desses recursos. Em 1969, através da Constituição imposta pela junta militar, o FPM foi reduzido para $5 \%$ do IR e IPI. A partir do final da década de 70, a participação do FPM sobre esses tributos foi sendo paulatinamente aumentada até 22,5\% do IR e IPI em 1993 (BARRETO, 1971; BRASIL, 1988). 


\section{CONSIDERAÇÕES FINAIS}

A intensidade da recente fragmentação das unidades de governo local, assim como a institucionalização de uma federação em três níveis, é um fenômeno político restrito ao Brasil. Essa multiplicação de governos locais não possui qualquer paralelo contemporâneo. Outros países registram somente a ocorrência de alguns eventos isolados, como a criação de new towns na França, Canadá, Austrália, Singapura etc. Todos resultantes de decisões tomadas pelos governos nacionais com o objetivo de planejar a expansão dos grandes centros urbanos através de novas cidades nos subúrbios. O contrário do que ocorreu no Brasil, onde decisões estaduais geraram milhares de pequenos municípios distantes das grandes aglomerações urbanas.

Nas últimas décadas do séc. XX, a multiplicação de distritos especiais nos Estados Unidos foi o único fenômeno que apresentou características similares à fragmentação municipal brasileira. O que há em comum entre esses dois fenômenos é a descentralização do processo decisório, a expressiva quantidade numérica e a razoável disseminação pelo território nacional da criação de novas unidades de governo local. Contudo, como os distritos especiais restringem-se à gestão de políticas específicas não é possível compará-los diretamente aos municípios brasileiros. Além disto, diferentemente dos municípios brasileiros, os distritos especiais geralmente possuem um grau muito limitado de autonomia. No Brasil, a autonomia municipal é padronizada e estabelecida pela Constituição Federal. Nos EUA, os distritos especiais e todos os outros tipos de governo local possuem graus diferenciados de autonomia política conforme delegação dos estados. Por fim, esse processo distingue-se do brasileiro porque os outros tipos de governos locais com propósitos gerais (condados, municipalidades e townships) não sofreram grandes oscilações no mesmo período.

Apesar da pouca similaridade, as investigações sobre as causas da criação e a variação quantitativa dos governos locais norte-americanos geraram considerações que possuem alguma relevância (heurística e comparativa) à compreensão da fragmentação municipal brasileira. Ao contrário do que ocorre no Brasil, as transferências intergovernamentais teriam efeitos periféricos na variação da quantidade de governos locais dos EUA. Primeiro, porque os distritos especiais $e$ escolares não se beneficiariam das transferências. Segundo, os efeitos desses recursos sobre o orçamento dos outros governos locais seriam marginais. Portanto, as transferências serviriam para a preservação de algumas unidades frágeis e não como estímulo à multiplicação dos governos locais. Além disto, não há uma regra estável sobre as transferências como a presente na Constituição brasileira. Nos EUA os recursos oscilam conforme decisões pontuais dos outros níveis de governo. Portanto, a indeterminação sobre as transferências fiscais não teria como estimular diretamente a fragmentação dos governos locais.

Mesmo não havendo estudos especificamente direcionados ao processo decisório, há um outro elemento comparativo que reforça a explicação da fragmentação dos governos locais pelos efeitos das regras institucionais sobre as decisões políticas. Nos EUA, as políticas tributárias federais e estaduais, que 
crescentemente limitaram a capacidade dos governos locais cobrar taxas ou impostos, estariam diretamente relacionadas ao incremento no número dos distritos especiais. Isto é, a alteração nas regras tributárias induziria os governos locais com propósitos gerais a transferir a administração de políticas específicas aos distritos especiais, criando novas unidades nesse processo. Essas considerações, apesar da grande diferenciação institucional entre os países, auxiliam na compreensão dos fatores determinantes do processo de fragmentação municipal brasileiro.

No Brasil, o arranjo institucional democrático, gerado pela Constituição de 1988 e existente antes de 1964, através de vários mecanismos específicos, estimulou a criação de milhares de novos municípios. Mais importante que isso, tornou possível que decisões favoráveis à fragmentação municipal predominassem no processo decisório estadual. Primeiro, porque a consolidação da descentralização fiscal garantiu a estabilidade das transferências fiscais aos municípios. Estas transferências estimularam a população e as lideranças políticas de pequenas localidades a demandar sua emancipação política.

$\mathrm{O}$ segundo mecanismo que favoreceu a criação de municípios foi a atribuição da regulamentação da fragmentação municipal aos estados. Isto ampliou drasticamente a disponibilidade de localidades desmembráveis e, portanto, a quantidade de proposições de criação de municípios que ingressavam nas assembléias, através de iniciativa dos deputados ou das lideranças locais.

Por último, vários mecanismos legais (federais e estaduais) instituíram uma tramitação dos pedidos de emancipação que atribuiu aos legislativos estaduais um papel preponderante no processo decisório da criação de municípios. Em alguns estados, isso predispôs o legislativo a conquistar uma maior autonomia frente ao executivo. Além disto, a participação popular na proposição legislativa, a prerrogativa exclusiva dos eleitores iniciarem a tramitação do processo e a manifestação popular no plebiscito, limitaram a capacidade de controle do executivo sobre o resultado legislativo.

Como o processo de fragmentação municipal não cessava nos estados, tal qual no regime militar o governo federal voltou a intervir para interromper a criação de novos municípios. Sem a alteração do regime político, a recentralização das regras através da Emenda 15/96 alterou o arranjo institucional que favorecia a fragmentação. Isto só foi possível porque o executivo federal vinculou a mudança constitucional à estabilidade fiscal. No entanto, como os estímulos fiscais aos eleitores locais e a lógica sobre as expectativas eleitorais dos parlamentares estaduais não foram modificados, novas decisões favoráveis às emancipações municipais provavelmente ocorrerão após o Congresso Nacional regulamentar a emenda $15 / 96$.

Além disto, o processo de criação de municípios apresenta questões sobre o papel dos mecanismos de democracia direta (plebiscito e exclusividade na iniciativa legislativa). As consultas plebiscitárias sobre a criação de municípios, juntamente com a iniciativa popular na legislação, representam o espaço mais extenso e significativo de investigação sobre os mecanismos de democracia direta no Brasil. O estudo da fragmentação municipal brasileira poderia 
servir como uma abertura para novas investigações sobre a relação entre democracia direta e processo decisório, cidadania e gestão dos governos locais.

A fragmentação municipal também apresenta questões ao estudo (descritivo e normativo) das instituições políticas brasileiras: a crítica do arranjo institucional do federalismo brasileiro, o papel dos níveis de governo, os mecanismos de estímulo à cooperação/competição entre as entidades governamentais. Neste sentido, creio que é interessante apresentar algumas considerações sobre a fragmentação municipal e o desenho institucional brasileiro.

Afinal, criar um município é um problema ou uma solução? Obviamente, a resposta depende do ponto de vista. Para os eleitores de pequenas localidades do interior significa uma maior oferta de emprego (geralmente públicos) e oportunidade de renda. Eventualmente, até pode significar a melhoria efetiva de alguns serviços públicos. Em conjunto, isso poderia reduzir o êxodo populacional das pequenas localidades para os grandes e médios centros urbanos. Caso esses efeitos ocorressem de fato, criar municípios poderia ser visto de forma mais pragmática do que as justificativas usuais: radicalização democrática e racionalidade na administração pública. Poderia ser entendido como uma política progressiva de redistribuição de renda ou de prevenção ao inchaço dos principais centros urbanos, com um grau de ineficiência variando conforme o custo das elites políticas locais e de suas demandas futuras.

Por outro lado, quando muitos municípios são criados em poucas unidades da federação e num tempo muito exíguo, isto gera um problema orçamentário. Tanto para os níveis mais abrangentes de governo, quanto para os outros municípios que não se fragmentaram e que dependem das transferências fiscais. Menos recursos nos antigos municípios e mais governantes locais com demandas legitimadas pelo status municipal (e por eleições) significam maior pressão por gastos públicos nos estados e na União. Isto parece inadmissível num momento em que austeridade administrativa, estabilidade econômica, equilíbrio orçamentário e superávit fiscal são tratados enquanto compromissos inalienáveis pelo consenso político dominante.

No passado recente a criação de municípios já foi definida como problema e como solução. As instituições estimularam ou reprimiram as emancipações numa oscilação que não variou, necessariamente, com o regime político. Em virtude disto, não me surpreenderia se num espaço curto de tempo uma nova institucionalidade descentralizadora substituísse a hegemonia centralista atual. A despeito dessa institucionalidade ciclotímica, creio que há três aspectos relacionados à divisão municipal que parecem problemáticos no arranjo institucional do federalismo brasileiro.

$\mathrm{O}$ primeiro aspecto vincula-se à forma de distribuição do FPM (Fundo de Participação dos Municípios) entre os municípios. $\mathrm{O}$ efeito redistributivo do fundo é transferir renda gerada nos grandes centros para as pequenas municipalidades. $\mathrm{O}$ resultado foi um estímulo crescente à fragmentação dos micromunicípios. Como os municípios mais populosos são menos dependentes do fundo, os grandes perdedores nessa fórmula de distribuição foram os pequenos e médios 
municípios do interior, sobretudo aqueles que não se dividiram. Se a lógica da distribuição do FPM é populacional, a institucionalização de uma distribuição per capita acabaria com o impacto negativo das emancipações nos municípios que não se dividem e restringiria o estímulo à fragmentação dos micromunicípios.

Outro aspecto se relaciona à instrumentalização do texto constitucional pelos objetivos políticos da coalizão de governo no nível federal (executivo e maioria legislativa). Durante a década de noventa houve um contínuo processo constituinte que, em geral, violou os princípios federativos institucionalizados no país de forma quase similar ao regime militar. A recentralização das regras sobre a fragmentação política interna dos estados foi somente um exemplo de fragilização da federação. Por mais justas que fossem as preocupações sobre o equilíbrio fiscal, essas não justificariam a violação da autonomia dos estados. Esta foi uma solução para suspender a onda emancipacionista. Eventualmente teve o apoio de alguns governadores incapazes de exercer suas preferências no processo decisório estadual. Contudo, possui sérias implicações sobre a concepção de quais limites devem ser impostos aos governantes na alteração das normas jurídicas fundamentais do Estado. Da mesma forma que é violada a federação, direitos individuais também poderiam ser alterados para atender aos objetivos pontuais dos governos.

Finalmente, há a própria forma de institucionalização dos governos locais no Brasil. Esses reúnem um alto grau de autonomia formal com uma padronização constitucional nas atribuições e prerrogativas.
Pressupor que unidades de governo local (com mil ou milhões de habitantes) tenham a mesma capacidade de exercer a autonomia política, gerar recursos fiscais, administrar as demandas locais e executar políticas públicas etc., beira o absurdo. A ausência de variações na definição das funções e competências dos municípios, pela via constitucional ou por delegação dos estados, cria expectativas irrealizáveis na maior parte dos governos locais. Enquanto os pequenos municípios comportam-se mais como grupos de interesse com status público do que como organizações governamentais, as grandes municipalidades são proibidas (pelas regras institucionais) de gerir políticas que poderiam executar com maior racionalidade, eficácia e controle público do que as esferas mais abrangentes. Enfim, é possível que a maior intensidade da fragmentação municipal recente tenha contribuído para a fragilidade da estabilidade política e orçamentária. Entretanto, creio que a ausência de unidades intermediárias de governo local entre os estados e os municípios e a uniformização da estrutura e da autonomia política dos municípios devem ter uma contribuição mais incisiva para os problemas da democracia brasileira que a multiplicação de municípios.

\section{REFERÊNCIAS}

ABRÚCIO, F. L. 1998. Os barões da federação: os governadores e a redemocratização brasileira. São Paulo: Hucitec/DCP-USP.

AFFONSO, R. B. A. e SILVA, P. L. B. (Orgs.). 1995a. Reforma tributária e federação. São Paulo: Ed. Unesp.

AFFONSO, R. B. A. e SILVA, P. L. B. (Orgs.). 1995b. A federação em perspectiva. São Paulo: FUNDAP. 
ALMEIDA, M. H. T. 1995. Federalismo e políticas sociais. RBCS. São Paulo, n. 28, ano 10.

ANDRADE, R. C. 1998. Processo de governo no município e no estado. São Paulo: EdUsp.

ARRETCHE, M. T. S. 1995. Descentralização, democracia, reforma do Estado e bem-estar: conceitos que não se equivalem. Caxambú/XIX ANPOCS, mimeo.

ARRETCHE, M. T. S. 1996. Mitos da descentralização - mais democracia e eficiência nas políticas públicas? RBCS. São Paulo, v. 11, n. 31.

ARRETCHE, M. T. S. 1998. O processo de descentralização das políticas sociais no Brasile seus determinantes. Campinas-SP, Tese (Doutorado em Ciências Sociais) - IFCH/ UNICAMP.

ARRETCHE, M. T. S. 1999. Políticas sociais no Brasil: descentralização em um estado federativo. RBCS. São Paulo, v. 14, n. 40.

ATALIBA, G. Regime federativo. In: FAORO, R. et al. 1987. Constituição e constituinte. São Paulo: Editora Revista dos Tribunais.

ATALIBA, G. Regime federativo. In: FAORO, R. et al. 1991. Criação de município - plebiscito. $R D P$, n. 98, ano 24.

AVELINO, G. 1994. Clientelismo e política no Brasil - revisitando velhos problemas. Novos Estudos CEBRAP. São Paulo, n. 38.

BAÊTA, A. M. C. 1989. Administração municipal e descentralização política: notas para uma discussão. Revista de Administração Pública. Rio de Janeiro, 23(4):100-107.

BARDO, J. e BARDO, D. 1983. A reexamination of subjective components of comunity satisfaction in a British new town. Journal of Social Psychology, v. 120, n. 1.

BARRETO, C. E. 1971. Constituições do Brasil. São Paulo: Edições Saraiva.

BRASIL. 1998. Constituição: República Federativa do Brasil. Brasília: Senado Federal/ Centro Gráfico.

BREMAEKER, F. E. J. 1991. Os novos municípios brasileiros instalados entre $1980 e$ 1990. Rio de Janeiro: IBAM.
BREMAEKER, F. E. J. 1993. Os novos municípios: surgimento, problemas e solução. $R A M$. Rio de Janeiro, v. 40, n. 206.

BREMAEKER, F. E. J. 1996. Limites à criação de novos municípios: a emenda constitucional. $\mathrm{n}$. 15. RAM. Rio de Janeiro, v. 43, n. 219.

BRIFFAULT, R. 1988. Localism in state constitutional law. Annals AAPSS, v. 496.

CAPUTO, D. A. 1975. General revenue sharing and american federalism: towards the year 2000 . Annals AAPSS, v. 419.

CASTRO, J. N. 1987. O poder regional autonomia municipal e constituinte. Revista de Administração Pública. Rio de Janeiro, 21(1):2-9.

COLUSSI, E. L. 1996. Estado Novo e municipalismo gaúcho. Passo Fundo: Ediupf.

CRAVER, G. A. 1999. An evaluation of the city of Danville-Pittsylvania county annexation (Virginia). Richmond/Virginia/USA,. Dissertação (Master of Urban and Regional Planning) College of Humanities and Sciences/Virginia Commonwealth University.

CRAWFORD, S. e OSTROM, E. 1995. A grammar of institutions. American Political Science Review, v. 89, n. 3.

DAGNAUD, M. 1981. Goursolas on new towns: a critical coment. International Journal of Urban and Regional Research, v. 5, n. 4.

DUCHACEK, I. D. 1988. State constitutional law in comparative perspective. Annals AAPSS, v. 496.

ESTADOS UNIDOS. BUREAU OF THE CENSUS. 1994. Census of governments government organization.

FIGUEIREDO, A. C. e LIMONGI, F. 1999. Executivo e legislativo na nova ordem constitucional. Rio de Janeiro: Ed. da FGV. FISCHER, Tânia (org.). 1993. Poder localgoverno e cidadania. Rio de Janeiro: Ed. da FGV.

FRANÇA. MINISTÉRE DES AFFAIRES ÉTRANGÈRES. 1996. La administracion territorial.

GIANNINI, C. M. C. 1990. Federação: a unidade na diversidade. Revista Cepam, ano 1, n. 1. 
GOMES, G. M. e MacDOWELL, M. C. 1997. Os elos frágeis da descentralização. Seminário Internacional sobre Federalismo e Governos Locais, La Plata, Argentina, mimeo.

GOURSOLAS, J. M. e ATLAS, M. 1980. New towns in the Paris metropolitan area. International Journal of Urban and Regional Research, v. 4, n. 3.

GRAVES, T. J. 1974. IGR and the executive branch: the new federalism. Annals AAPSS, v. 416.

GRUMM, J. G. e MURPHY, R. D. 1974. Dillon's rule reconsidered. Annals AAPSS, v. 416.

HALL, P. e TAYLOR, R. 1997. La Science Politique et les trois néo-institutionnalismes. Revue Française Science Politique, v. 47, n. 3-4.

HILLENBRAND, B. F. 1974. Counties: the emerging force. Annals AAPSS, v. 416.

IMMERGUT, E. 1996. The normative roots of the new institutionalism: historical institutionalism and comparative policy studies. Baden-Baden, mimeo.

JACOBI, Pedro. 1990. Descentralização municipal. Revista CEPAM. São Paulo, ano I, n.3.

JACOBI, Pedro. 1991. Os municípios e a participação: desafios e alternativas. Revista de Administração Municipal. Rio de Janeiro, v. 38, n. 198.

KLERING, L. R. 1991. Desempenho dos novos municípios - emancipações políticas do RS na década de 80: razões, histórico e diretrizes. In.: MINCARONE, M. Emancipação: liberdade para prosperar. Rio Grande do Sul: Assembléia Legislativa.

LIMONGI, F. 1994. O novo institucionalismo e os estudos legislativos. BIB. São Paulo, n. 37.

LOWNDES, V. 1996. Varieties of new institutionalism: a critical appraisal. Public Administration, v. 74.

MACMANUS, S. A. 1990. Financing federal, state, and local governments in the 1990s. Annals AAPSS, v. 509,.

MARANDO, V. L. 1973. Voting in city-county consolidation referenda. The Western Political Quarterly.
MEDINA, A. V. A. 1987. Tarefas ou Poder: o que descentralizar? Cadernos de Pesquisa. São Paulo, (60):45-7.

MELLO, D. L. 1991. Descentralização, papel dos governos locais no processo de desenvolvimento nacional e recursos financeiros necessários para que os governos locais possam cumprir seu papel. Revista de Administração Pública. Rio de Janeiro, 25(4):199-217.

MELLO, D. L. 1993. O governo municipal brasileiro: uma visão comparativa com outros países. Revista de Administração Pública. Rio de Janeiro, 27(4):36-53.

MELLO, D. L. 1992. A multiplicação dos municípios no Brasil. RAM. Rio de Janeiro, v. 39, n. 203

MELO, M. A. B. C. 1993. Municipalismo, nation building e a modernização do Estado no Brasil. RBCS. São Paulo, n. 23, ano 8.

MESQUITA, Z. 1992. Emancipações no RS: alguns elementos para reflexão. Análise Conjuntural, Porto Alegre, v. 20.

MINCARONE, M. 1991. Emancipação: liberdade para prosperar. Rio Grande do Sul: Assembléia Legislativa.

MONTORO, E. A. F. 1974. A organização do município na federação brasileira. São Paulo, Tese (Doutorado em Ciências Jurídicas e Sociais) PUC/SP.

MOUW, C. J. e MACKUEN, M. B. 1992. The strategic agenda in legislative politics. American Political Science Review, v. 86, n. 1.

NATHAN, R. P. 1975. Federalism and the shifting nature of fiscal relations. Annals AAPSS, v. 419 .

NATHAN, R. P. e LAGO, J. R. 1990.

Intergovernmental fiscal roles and relations. Annals AAPSS, v. 509.

PAGANO, M. A. 1990. State-local relation in the 1990s. Annals AAPSS, v. 509.

PEEL, M. 1995. The rise and fall of social mix in an Australian new town. Journal of Urban History, v. 22, n. 1. 
RUTLEDGE, P. J. 1974. Federal-local relations and the mission of the city. Annals AAPSS, v. 416.

SANTOS, F. G. M. 2001. O poder legislativo nos estados: diversidade e convergência. Rio de Janeiro: EdFGV.

SEYLER, W. C. 1974. Interlocal relations: cooperation. Annals AAPSS, v. 416.

SHIKIDA, C. D. 1998. Emancipação de municípios em Minas Gerais (1995): uma abordagem Novo-Institucionalista e de Escolha Pública. São Paulo-SP, Dissertação de Mestrado (Faculdade de Economia, Administração e Contabilidade) - USP.

SKABURSKIS, A. 1989. Options the developing resource towns: the effects of increasing government involvement in new town development. Journal of Architectural and Planning Research, v. 6, n. 4.

SOARES, M. M. 1998. Federação, democracia e instituições políticas. Lua Nova, n. 44, 1998.

TEIXEIRA, E. 1994. Ações coletivas e poder local - um mapeamento. Cadernos do CEAS, n. 154

TEIXEIRA, E. 1992. Cidadania e poder local.Cadernos do CEAS, n. 136.

TEUNE, H. 1995. Local government and democratic political development. Annals AAPSS, v. 540 .

THELEN, K. e STEINMO, S. 1992. Historical institutionalism in comparative politics. In.:

STEINMO, S. et al. (Eds.). Structuring politics: historical institutionalism in comparative analysis. Cambridge University Press.

TOBAR, F. 1991. O conceito de descentralização: usos e abusos. Planejamento e Políticas Públicas. Rio de Janeiro, n. 5.
TOMIO, F. R. L. 1998. Explosão municipal: notas de uma pesquisa. In.: FLÔRES, J. R. A. e NATIVIDADE, M. O. (Orgs.). Política, cultura \& sociedade. Santa Maria: UFSM/PRE/DSP.

TOMIO, F. R. L. 2002a. Instituições, processo decisório e relações executivo-legislativo nos estados: estudo comparativo sobre o processo de criação de municípios após a Constituição de 1988. Campinas-SP. Tese de Doutorado (Doutorado em Ciências Sociais) - IFCH/ UNICAMP.

TOMIO, F. R. L. 2002b. A criação de municípios após a constituição de 1988. RBCS, v. 17, n. 48.

UGA, M. A. D. 1991. Descentralização e democracia: o outro lado da moeda. Planejamento e Políticas Públicas. Rio de Janeiro, n. 5.

VASOO, S. 1988. The development of new towns in Hong Kong and Singapore: some social consequences. International Social Work, v. 31, n. 2.

WRIGHT, D. S. 1975. Revenue sharing and structural features of american federalism. Annals AAPSS, v. 419.

WRIGHT, D. S. 1974. Intergovernmental relations: an analytical overview. Annals AAPSS, v. 416 .

WRIGHT, D. S. 1990. Policy shift in the politics and administration of intergovernmental relations, 1930s-1990s. Annals AAPSS, v. 509.

ZIMMERMAN, J. F. 1974. The metropolitan area problem. Annals AAPSS, v. 416.

ZIMMERMAN, J. F. 1990. Regulating intergovernmental relations in the 1990s. Annals AAPSS, v. 509. 